\title{
Newcastle - University \\ Desiccation cracking at field scale on a vegetated infrastructure embankment
}

Author 1

- Zelong $\mathrm{Yu}^{* 1}$, BEng MSc PhD

- https://orcid.org/0000-0002-4912-5096

Author 2

- Oboho Okon Eminue*, BSc MSc PhD

- https://orcid.org/0000-0002-6384-074X

Author 3

- Ross Stirling*, BSc MSc PhD

- https://orcid.org/0000-0002-0069-6621

Author 4

- Colin Davie*, BEng MSc PhD

- https://orcid.org/0000-0003-2770-9178

Author 5

- Stephanie Glendinning*. BSc PhD

- https://orcid.org/0000-0002-5012-0487

* School of Engineering, Newcastle University, Newcastle upon Tyne, UK

${ }^{1}$ Corresponding author, Email: Zelong.Yu@newcastle.ac.uk

Journal:

Géotechnique Letters, Volume 11, Issue 1

Accepted date:

08 January 2021

Published online:

13 January 2021

Version of attached file:

Accepted version

Peer-review status of attached file:

Peer-reviewed

Citation for published item:

Yu, Z., Eminue, O.O., Stirling, R., Davie, C. and Glendinning, S., 2021. Desiccation cracking at field scale on a vegetated infrastructure embankment. Géotechnique Letters, Volume 11, Issue 1, pp.1-21. DOI: https://doi.org/10.1680/jgele.20.00108. 


\begin{abstract}
This paper presents a desiccation crack monitoring campaign conducted on a full-scale, vegetated infrastructure embankment subjected to one-year of seasonally variable weather. The field survey involved direct measurement of naturally developed, annually reoccuring cracks in a heavily instrumented, clay fill embankment (BIONICS, Newcastle University). Transient crack morphology was captured in terms of opening width, length and depth, in addition to meteorological and near-surface soil hydrological conditions. In order to assess any correlation between crack development and weatherdriven changes in near surface soil conditions, the volume of cracks was estimated using an empirically derived equation. This work identified crack behaviour in four stages: initiation, expansion, contraction and closure. These stages and the distribution of cracks on the slope are closely related to prevailing atmospheric conditions, namely wind direction, relative humidity, precipitation and potential evapotranspiration. These ultimately govern the soil hydrological conditions in the near-surface, as manifested in the presented matric potential and volumetric water content data. Linearly descrete cracks are shown to form under such conditions in contrary to the polygonal patterns typically reported under laboratory conditions. Crack length growth terminates prior to full volumetric maturation with crack depth dominating the dynamic response regardless of overall crack size.
\end{abstract}

\title{
Keywords chosen from ICE Publishing list
}

Field instrumentation; Expansive soils; Embankments; Full-scale tests;

\section{List of notations}

$d_{1} \quad$ is the depth of the first measurement point $(\mathrm{mm})$

$d_{2} \quad$ is the depth of the second measurement point $(\mathrm{mm})$

$L \quad$ is the length between two measurement points $(\mathrm{mm})$

$V \quad$ is the volume of the crack $(\mathrm{mm})$

$W_{1} \quad$ is the width of the first measurement point $(\mathrm{mm})$

$W_{2} \quad$ is the width of the second measurement point $(\mathrm{mm})$

$E T_{0}$ is reference evapotranspiration ( $\mathrm{mm} /$ day)

$R_{n} \quad$ is mean daily net radiation at the crop surface $\left(\mathrm{MJ} / \mathrm{m}^{2}\right)$

$G \quad$ is mean daily soil heat flux density $\left(\mathrm{MJ} / \mathrm{m}^{2}\right)$

$T$ is mean daily air temperature at $2 \mathrm{~m}$ height $\left({ }^{\circ} \mathrm{C}\right)$

$u_{2} \quad$ is mean daily wind speed at $2 \mathrm{~m}$ height $(\mathrm{m} / \mathrm{s})$

$e_{s} \quad$ is mean daily saturation vapour pressure $(\mathrm{kPa})$

$e_{a} \quad$ is mean daily actual vapour pressure $(\mathrm{kPa}]$

$e_{s}-e_{a}$ is mean daily saturation vapour pressure deficit $(\mathrm{kPa})$

$\Delta \quad$ is mean daily slope vapour pressure curve $\left(\mathrm{kPa} /{ }^{\circ} \mathrm{C}\right)$

$\gamma \quad$ is mean daily psychrometric constant $\left(\mathrm{kPa} /{ }^{\circ} \mathrm{C}\right)$ 


\section{Introduction}

Cracking is a common phenomenon in unsaturated, cohesive soils subjected to drying and is of concern in a range of disciplines, including agriculture, geotechnical engineering, mining and resource management. The implications of cracking on the stability of infrastructure slopes has been well documented, including its contribution to the progressive deterioration of such assets (Stirling et al., 2020). In order to understand the mechanism of desiccation cracking, it is important to be able to adequately parameterise and characterise behaviour. There have been many approaches, including manual measurement (Zein El Abedine and Robinson, 1971; Dasog et al., 1988; RingroseVoase and Sanidad, 1996; Rivera, 2008; Dyer et al., 2009; Stewart et al., 2012), image analysis (Tang et al., 2008; Peron et al., 2009b; Costa et al., 2013; Sanchez et al., 2013; Gadi et al., 2017; Zhang et al., 2019; Cheng et al., 2020a), fractal analysis (Vallejo, 2009; Lu et al., 2016), X-ray computed tomography (Anderson et al., 1982; Viggiani et al., 2014; Tang et al., 2019; Julina and Thyagaraj, 2019), electrical resistivity tomography (Hen-Jones et al., 2017; Tang et al., 2018; An et al., 2020), ground penetrating radar (Benson, 1995; Levatti et al., 2017), distributed optical fiber sensing technique (Cheng et al., 2020b) and numerical modelling (Ayad et al., 1997; Peron et al., 2009a; AMARASIRI and KODIKARA, 2013; Sánchez et al., 2014; Stirling et al., 2017; Levatti et al., 2019; Tran et al., 2019). These approaches typically focus on crack production in a laboratory setting using processed clays, often from slurried states. Therefore, their scale is rarely representative of field conditions and cannot account for heterogeneity in full-scale structures and the influence of vegetation, fundamental considerations in stress-strain localisation. Furthermore, the existing literature from the field takes a snap-shot in time approach to addressing what is actually a transient behaviour that is highly dependent on seasonally variable conditions. This study presents for the first time, a prolonged, manual crack survey across the an embankment alongside contemporaneous soil water content, matric suction and meteorological data to provide evidence of fieldscale cracking behaviour over an annual timescale. The objectives are to: define cracking style on vegetated infrastructure embankments; present evidence of natural environmental factors that influence the distribution of cracking; outline the relationship between seasonally variable weather conditions, soil hydrological conditions and the transient response of cracks; and provide a comprehensive time series dataset which enables field cracking to be better understood.

\section{The Embankment}

The BIONICS embankment, located in Northumberland (UK), is $6 \mathrm{~m}$ high, $90 \mathrm{~m}$ long and orientated approximately east-west with a 1:2 slope, representative of typical UK infrastructure (Figure 1). The embankment comprises four panels with the central panels constructed to Highways England specifications (termed 'well-compacted') and two outermost sections built with reduced compaction to represent poorly constructed/heterogeneous rail embankments. Further details on the design and construction are provided in Hughes et al. (2009); its behaviour over a 4-year period is further discussed by Glendinning et al. (2014) and longer-term aspects by Stirling et al. (2020).

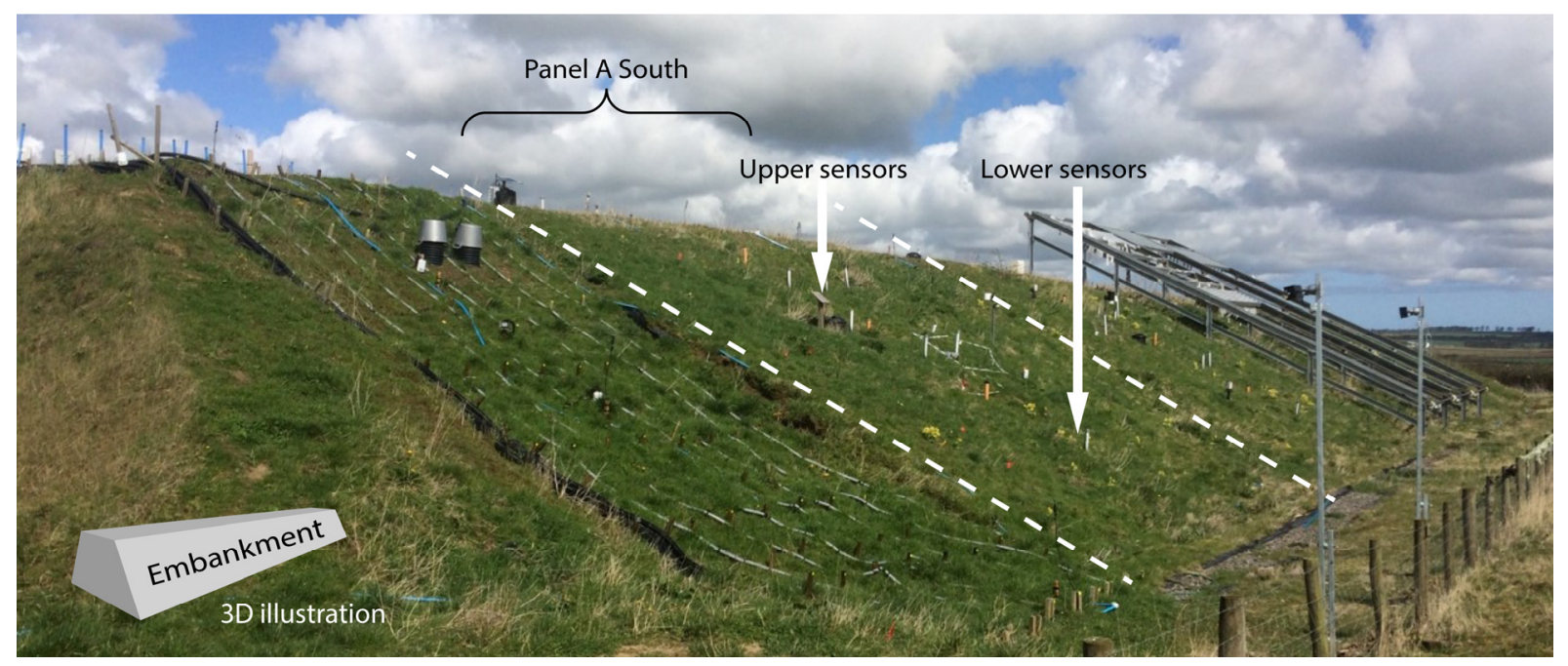

Figure 1. Photograph of the BIONICS Research Embankment looking northeast. 


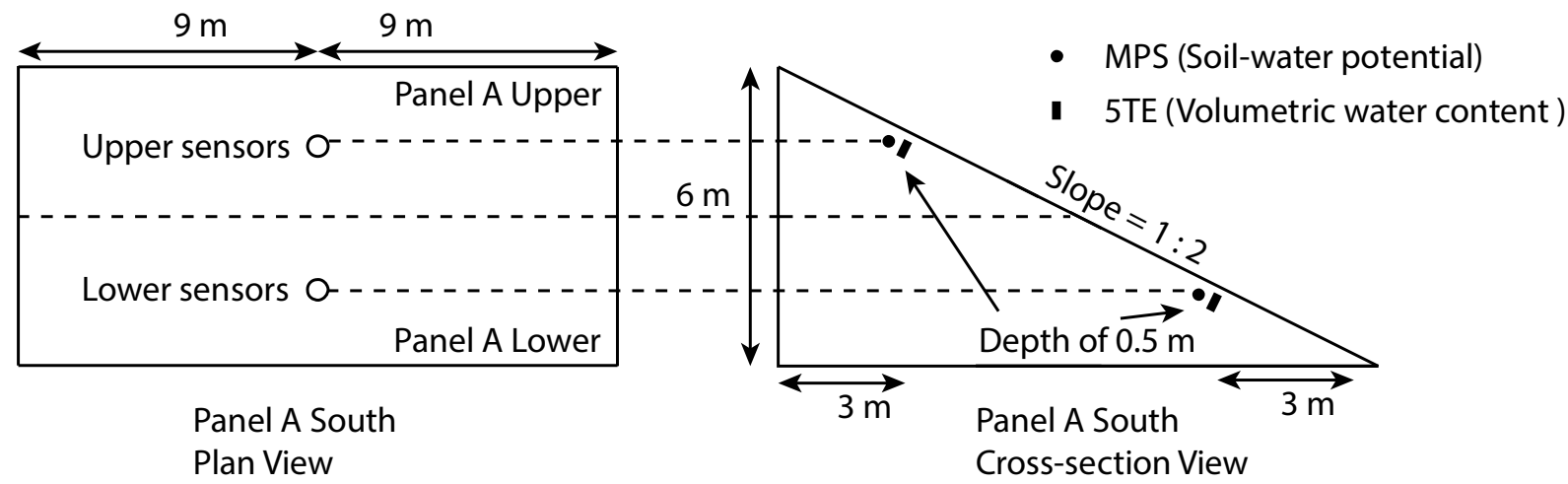

Figure 2. Layout of sensors.

\subsection{Slope vegetation}

The slopes were seeded immediately after placement of $300 \mathrm{~mm}$ topsoil in 2006, with a grassland/highways mixture. Vegetation surveys conducted in the period 2014-2015 indicated a shift towards wind-blown colonisation by additional species on the south facing slope. The northern aspect is characterised by lower plant diversity, predominantly grasses (e.g. Alopecurus pratense and Lolium perenne) while the southern aspect displays a higher diversity of wildflowers (e.g. Leucanthemum vulgare, Filipendula ulmaria, Achillea millefolium and Knautia arvensis). Excavations indicated an average rooting depth of approximately $400 \mathrm{~mm}$, below which rooting density diminishes.

\subsection{Embankment fill}

The construction fill (Durham Lower Boulder Clay) is a glacial till, typical of many infrastructure embankments in the northern UK. It is a well-graded $(>2 \mu \mathrm{m})$, intermediate plasticity sandy clay with liquid and plastic limits, $42 \%$ and $22 \%$, respectively, and a shrinkage limit of $14 \%$. The particle size distribution shows the material comprises gravel $12 \%$, sand $16 \%$, silt $35 \%$ and clay $37 \%$. A maximum dry density of $1.82 \mathrm{Mg} / \mathrm{m}^{3}$ at $15 \%$ optimum water content was established by normal Proctor (light) compaction testing. The dry density for poor-compacted and well-compacted panel are 1.6 and $1.7 \mathrm{Mg} / \mathrm{m}^{3}$, respectively. Results of quantitative XRD analyses on the $<2 \mu \mathrm{m}$ fraction indicate clay mineral assemblages comprising variable amounts of illite/smectite (ranging $42-54 \%$, with a mean of $49 \%$ ), chlorite/smectite (3-7\% range, mean $5 \%$ ), illite (16$26 \%$ range, mean $19 \%$ ) and kaolinite $(23-31 \%$ range, mean $26 \%$ ).

\subsection{In situ monitoring}

Instrumentation included buried soil hydrology sensors and dual aspect meteorological monitoring.
The buried sensors employed were manufactured by Decagon Devices, namely the 5TE and MPS-1 and MPS-2/6 models. The 5TE measures volumetric water content, electrical conductivity and soil temperature (Decagon Devices, 2016). The MPS range of instruments measure soil water potential (matric suction) within the range $-9 \mathrm{kPa}$ to $-100,000$ $\mathrm{kPa}$, later models are also capable of measuring soil temperature (Decagon Devices, 2009, 2017). In the interests of brevity, full technical specifications may be accessed directly from the manufacture's literature. These sensors are located at $0.5 \mathrm{~m}$ depth in the middle of the upper and lower sections on the presented western 'poorly' compacted panel (Figure 2). A weather station is positioned on the crest of the embankment, with a further two, connected stations on the north and south slopes. Besides precipitation, the meteorological parameters recorded, and available from (Yu et al., 2020), also enabled the calculation of reference evapotranspiration using the Penman-Monteith estimation provided in Equation 1 (Allen et al., 1998).

$$
E T_{o}=\frac{0.408 \Delta\left(R_{n}-G\right)+\gamma_{T+273} u_{2\left(e_{s}-e_{a}\right)}}{\Delta+\gamma\left(1+0.34 u_{2}\right)}
$$

\section{Crack measurement and characterisation}

Cracking has been observed since 2009 (2 years post-construction). This work presents manual crack surveying (approximately weekly) over a one-year study period. Crack observations include their location, length, width at regular intervals and approximate depth and were established using a thin flexible, graduated probe pushed in until refusal by light hand pressure (Eminue, 2018). This process is labour intensive and relies upon successful discovery of crack sites amongst dense vegetationcover, up to $0.5 \mathrm{~m}$ in height in Spring-Summer. This factor is particularly important in the discovery of new cracks. Once established, crack sites can be reliably returned to repeatedly. 
In order to correlate crack development with weather-driven changes in near-surface hydrology, the volume of the cracks was estimated using an empirically derived geometric relation where volume,

$V=\frac{1}{3} L\left[\left(\frac{1}{2} w_{1} d_{1}\right)+\left(\frac{1}{2} w_{2} d_{2}\right)+\sqrt{\left(\frac{1}{2} w_{1} d_{1}\right)\left(\frac{1}{2} w_{2} d_{2}\right)}\right]$

In this equation, the shape of a crack section having width $w$, depth $d$ and length $L$ between any two measurement points, is assumed as a triangular pyramid or fulcrum (Figure 3). This satisfies theorem 522 and 524 (Holgate, 1901) relating cross-sectional volume of fulcrum to the area (i.e. product of the measured crack length and width) and altitude (depth).

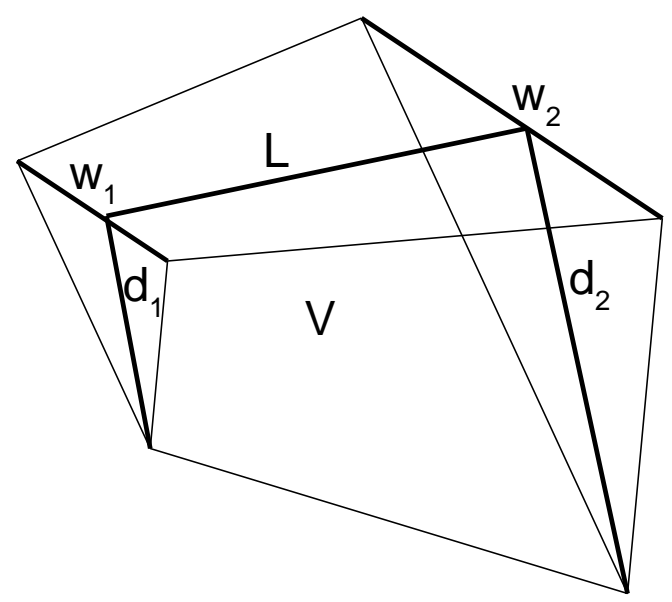

Figure 3. Geometry of crack section: Width $\left(w_{1}\right)$ and depth $\left(d_{1}\right)$ of first measurement point; Width $\left(w_{2}\right)$ and depth $\left(d_{2}\right)$ of second measurement point; Crack length $(L)$ is the gap between the two measurement points; the pyramid volume $(\mathrm{V})$.

\section{Results and discussion}

The full dataset presented herein is openly accessible via the Newcastle University data repository (Yu et al., 2020).

The majority of cracking occurs on the poorly compacted Panel A, as shown in Figure 4a, with 11 of the total 19 cracks present on the south slope (Figure 4b). Six cracks (\#4-8 and \#11) were found on the upper section and five cracks (\#1-3 and \#9-10) on the lower section. Cracks \#4-11 had been identified by researchers from the same group prior to the start of this survey and are considered longstanding features although are comparable in scale and behaviour to those identified at the start of this survey. Figure 5 illustrates the discrete, linear cracking style typically seen in this context which is hypothesised to be due to the presence of dense vegetation. This style of cracking is in contrast to the branching, connected polygonal style typically seen in laboratory experiments (Tang et al., 2008, 2011; Costa et al., 2013; Bordoloi et al., 2018; Cheng et al., 2020a) and sparcely vegetated field sites (Dyer et al., 2009; Li and Zhang, 2011). The key mechanical difference between vegetated and non-vegetated soils is the permeation of roots which influences both the generation of suction ( $\mathrm{Ng}$ et al., 2019) and tensile strength in the form of fiberous root reinforcement (Tang et al., 2012). The work of Bordoloi et al. (2018) investigated the influence of vegetation on cracking with a dedicated laboratory study. They found that grass species reduced the maximum crack intensity factor by $20 \%$ compared to bare soil. However, it is difficult to achieve the same maturity and density of vegetation as found in the field in small-scale laboratory experiments. Wind roses (Figure 4c \& 4d) demonstrate the difference in exposure across the embankment. The prevailing wind direction is southwesterly with maximum wind speeds between 10-12 $\mathrm{ms}^{-1}$. The wind directions recorded on both sides display a sheltering effect due to the embankment orientation with maximum magnitudes on the north slope supressed. Besides wind exposure, the southern aspect will also experience greater solar radiation and longer daylight hours. Exposure to the prevailing wind and solar radiation will promote drying on Panel A south which together with a greater diversity of vegetation, may be responsible for the majority of cracking being observed on this slope.

This study will focus on the most crack-active slope, Panel A south. Volumetric time-series data for all 11 cracks are presented in Figure 6 alongside the respective meteorological and near-surface soil conditions. The daily reference evapotranspiration (ETo) trend shows a typical seasonal trend, peaking mid-summer and negligible mid-winter, this trend is inverse to mean daily relative humidity $(\mathrm{RH})$. The maximum suction on the upper section (430 kPa) is greater than that on the lower section (102 kPa). Accordingly, the minimum volumetric water content (VWC) on the upper section (25\%) is lower than that at lower section (28\%), although both show a similar maximum (41\%), approximating to full saturation. At the time of construction, core cutter samples taken from this panel provided an average porosity of $38 \%$ (Glendinning et al., 2014). A dry period is defined by suction generation between July and midNovember, coinciding with peak ETo (minimum $\mathrm{RH}$ ) and the onset of rainfall in the absence of ETo, 


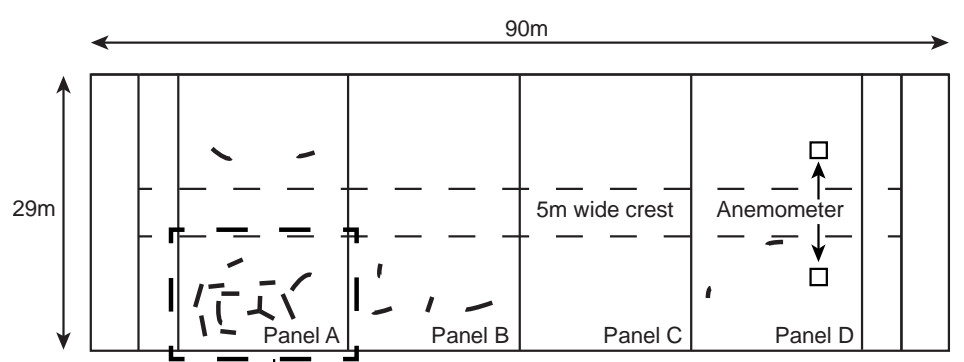

(a)

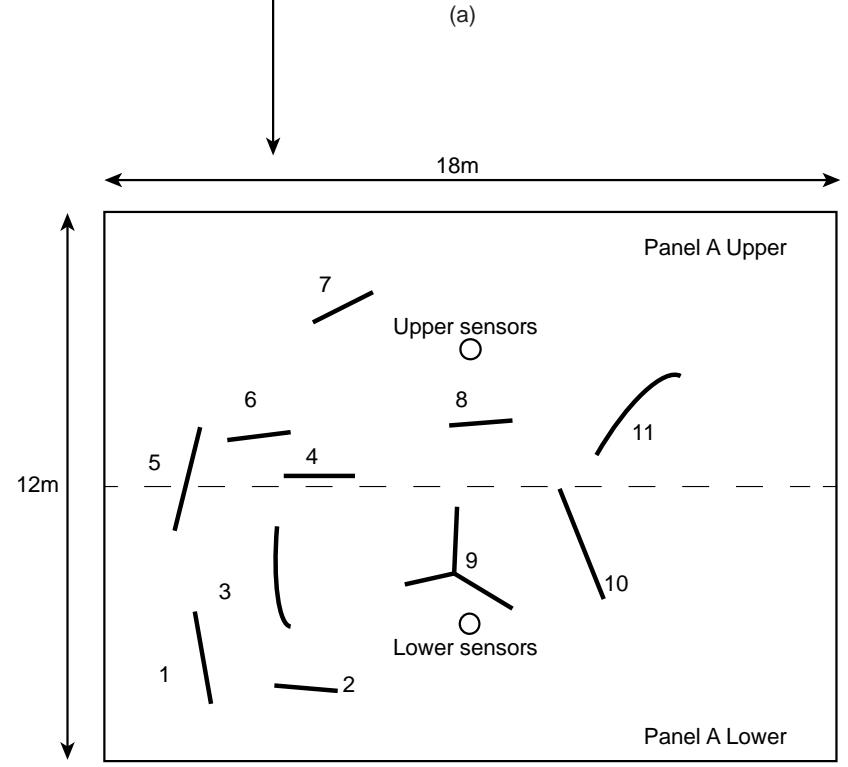

(b)

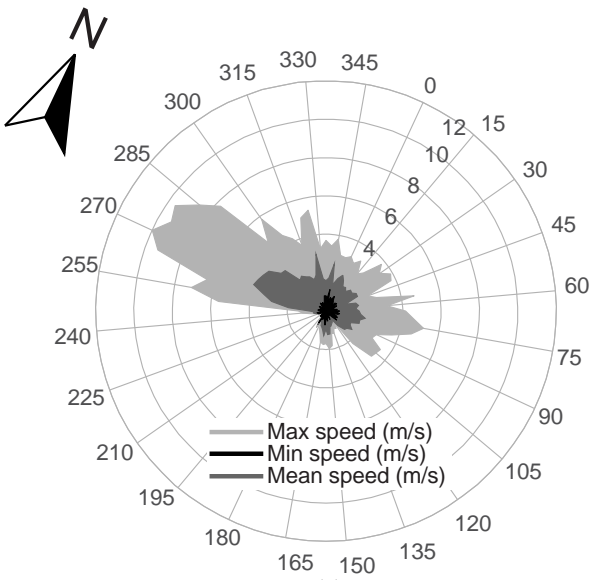

(c)

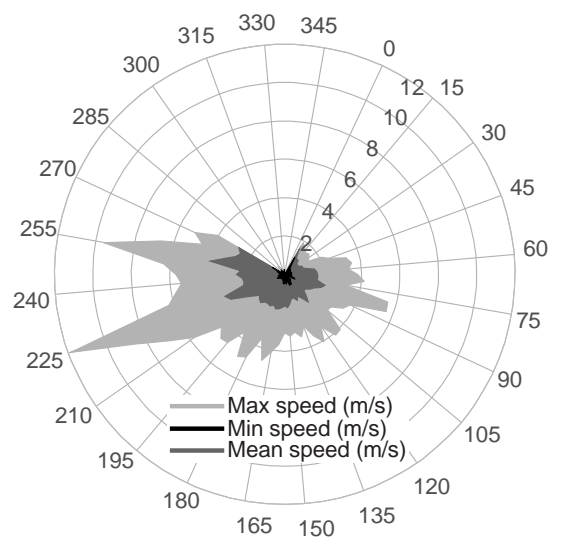

(d)

Figure 4. Embankment layout showing crack distribution and wind exposure with respect to slope aspect. (a) Overview of cracks at the BIONICS embankment; (b) Crack distribution on the upper and lower $(6 \mathrm{~m})$ halves of Panel A South; Wind exposure on (c) north slope and (d) south slope.

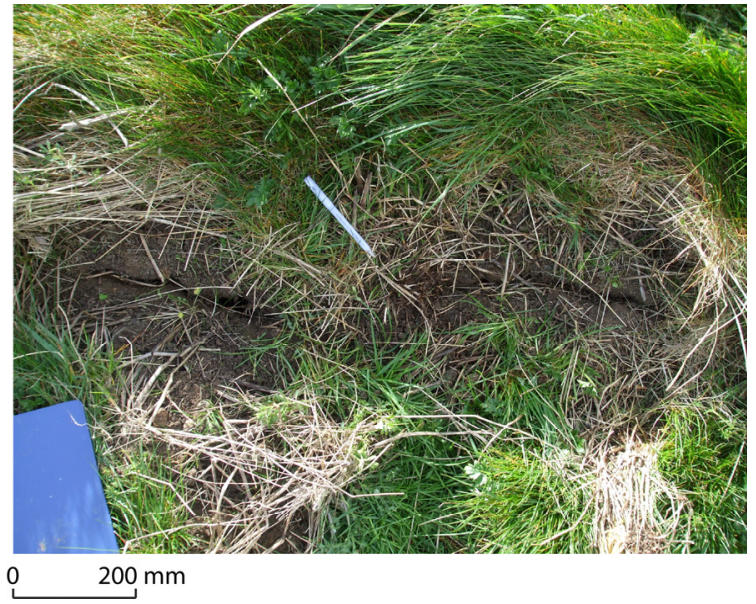

Figure 5. Photograph of crack \#10, a representative embankment crack.

respectively. During this dry period, water contents are lower, with correspondingly higher suctions, in the upper section. This is thought be the result of several factors: (i) the water table would be expected to lower from the top of the embankment under gravity; (ii) the upper secion is exposed to winddriven drying to a greater degree than the lower section (closer in elevation to the surrounding topography); (iii) the lower section receives a larger volume of runoff as the catchment above is greater; and (iv) there exists heterogeneity in the material and vegetative cover. The end of the dry period is marked by a net positive water balance entering the winter, leading to the rapid dissipation of suction followed immediately by the return to saturated water content, the lag being a result of the non-linear soil-water retention characteristics of the embankment fill material.

Based on crack volumes in conjunction with meteorological and soil hydrological trends, the monitored period may be divided into 4 stages: 


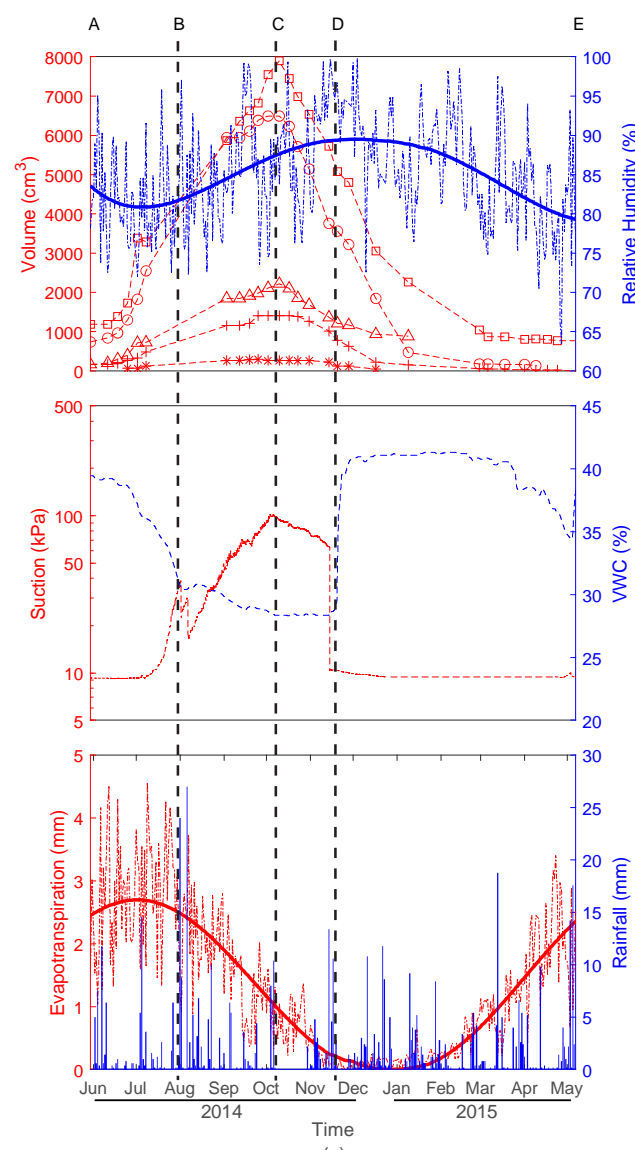

(a)

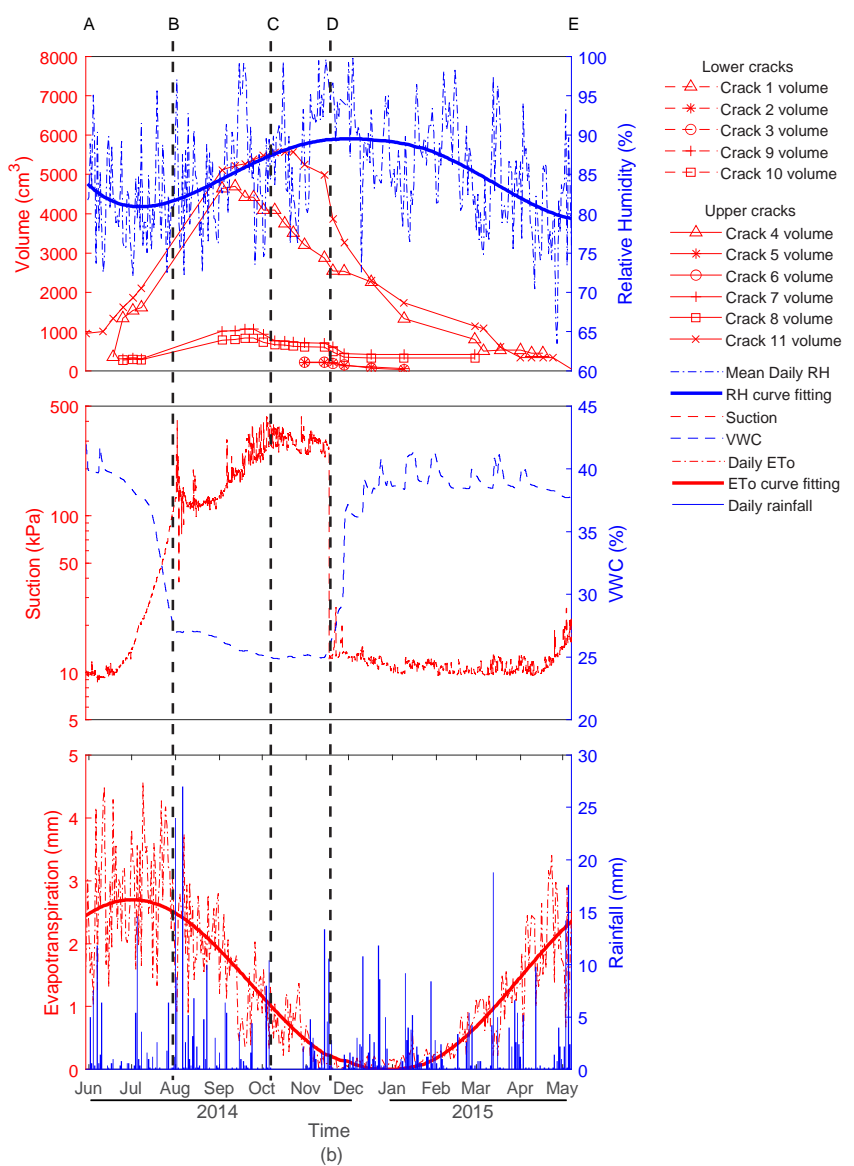

Figure 6. Crack volume behaviour with respect to atmospheric and soil hydrological conditions on the (a) lower section and (b) upper section.

I. Initiation - AB (June - August): High ETo (low $\mathrm{RH}$ ) leads to rapidly decreasing $\mathrm{VWC}$ and ultimately, increasing suction. Net drying leads to the initiation of crack opening on both sections.

II. Expansion - BC (August - October): Suction continues to be generated in both sections, coincident with sustained low VWC. Crack volumes continue to increase to their maximum despite falling ETo and heavy rainfall events in early August.

III. Contraction - CD (October - Mid November): Despite maintaining low VWC, falling ETo rates, increasing $\mathrm{RH}$ and consecutive days of rainfall lead to a minor reduction in suction and onset of decreasing crack volumes.

IV. Closure - DE (Mid November - May): Rapid loss of suction is associated with resaturation as a result of sustained rainfall and negligible ETo. Suction and VWC subsequently remain constant through this dominantly wet period. Crack volumes continue to decrease until eventually reaching their initial, 'closed' state.
Several cracks were observed to reach comparable depths to the buried sensors, as seen in Figure 8 and Figure 7. Measurements were taken at $0.5 \mathrm{~m}$ to avoid the initiation of cracking immediately above the instruments. This would invalidate measurements due to the accelerated infiltration of runoff from upslope to the monitored depth. Therefore, there may be assumed a lag between the generation of suction at the surface during drying, where crack widths and lengths are measured, and that recorded at $0.5 \mathrm{~m}$. Partial saturation and the generation of suctions at the surface may be inferred from reduced atmospheric $\mathrm{RH}$. It may be noted that only one crack

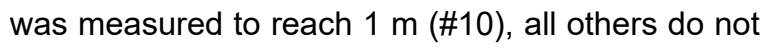
extend below $0.5 \mathrm{~m}$.

To aid comparison, survey results presented in Figure 8 and Figure 7 are classified into small $(<500$ $\left.\mathrm{cm}^{3}\right)$, medium $\left(500<\mathrm{V}<3000 \mathrm{~cm}^{3}\right)$ and large cracks $\left(>3000 \mathrm{~cm}^{3}\right)$. Irrespective of crack size, width and depth are shown to be most dynamic and thus, influence the volume trend to the greatest degree. That is, steadily increasing crack volume to a peak occurring simultaneously with greatest depth and 

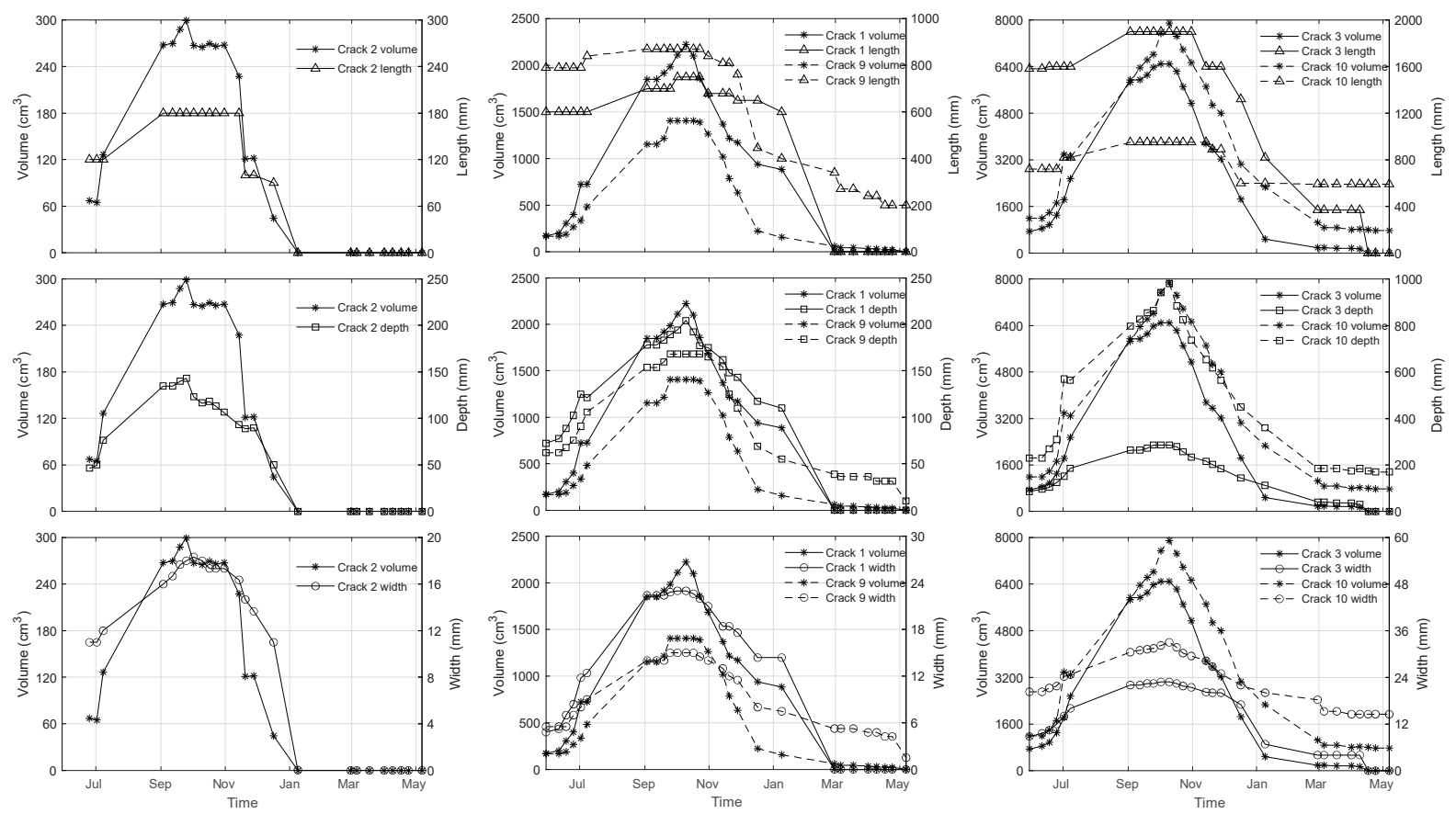

Figure 8. Crack dimension measurements (lengths, mean depth and mean width) from the lower slope: (a) Small cracks; (b) Medium cracks; and (c) Large cracks.
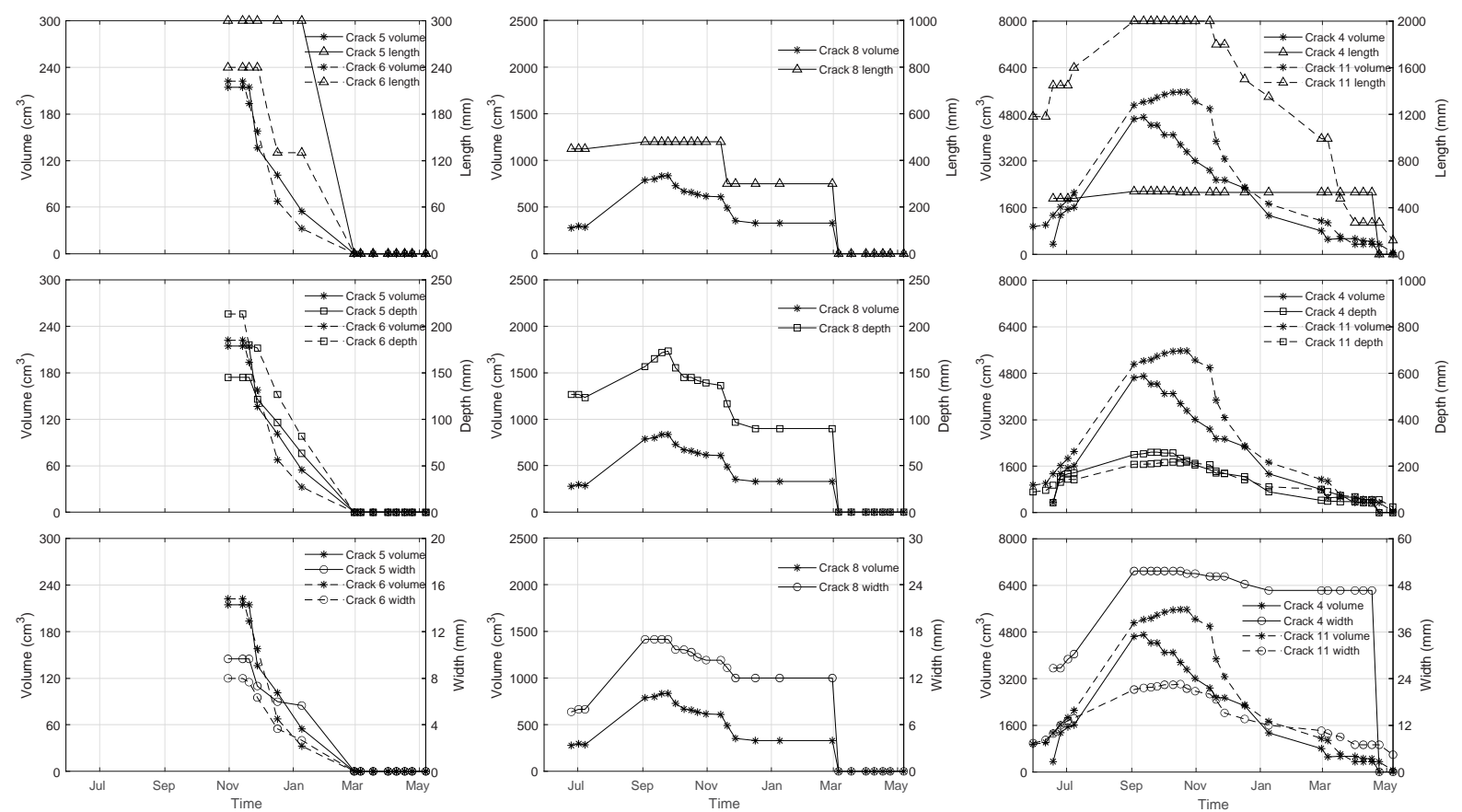

Figure 7. Crack dimension measurements (lengths, mean depth and mean width) from the upper slope: (a) Small cracks; (b) Medium cracks; and (c) Large cracks.

width. Crack lengths are characterised by a stepwise trend and reach a sustained maximum while volume continues to increase, largely driven by increasing depth as widths remain small in magnitude. Closure of cracks is the reverse of this process with volume reduction driven by decreasing depth, and to a lesser extent width, prior to a reduction in length.
The mechanism behind depth propagation dominating crack volume development remains an area necessitating further research and improved measurement techniques. A reducing root density, and thereby reinforcement, with depth may influence the ability of the crack tip to progress at the expense of limited surface aperture growth. Alternatively, 
drying at the surface leads to soil at depth being at a higher relative water content, leading to the crack tip favouring propagation into weaker material than at the surface. Stirling et al. $(2015,2017)$ showed that tensile strength increased exponentially with decreasing water content in the same clay fill, which supports the notion that cracks may preferentially extend downward at the expense of lengthening.

\section{Conclusions}

Desiccation cracking in a full-scale, vegetated embankment has been studied, which for the first time, presents long-term crack dimension monitoring in the field and contextual meteorological and soil hydrological data. Results show that the distribution of cracking was heavily related to prevailing wind direction (exposure) and crack response is driven by seasonal changes in meteorological and soil hydrological conditions. Crack behaviour over an annual cycle is impacted little by short-term weather events. Crack volume development has been observed to follow four stages: initiation, expansion, contraction and closure. Although driven by seasonal meteorological cycles, these behaviours have been linked to progressive drying and the generation, maintenance and eventual loss of matric suction over the 1-year monitoring period. The manual crack surveying has indicated that regardless of overall crack size, width and depth have the most dynamic response. Cracks tend to reach a terminal length at which depth propagation continues preferentially, and is reversed upon closure. Cracking under these conditions are linear features, in contrast to polygonal patterns produced under non- or sparsely vegetated conditions. The data presented here is intended to aid the necessary transition of laboratory scale desiccation cracking research to more realistic, full-scale and natural conditions. Only in this way can the dynamic influence of cracking on infrastructure slope hydrology and stability under changing and ever more extreme weather be better understood.

\section{Acknowledgements}

The work presented is an output of the collaborative programme grant ACHILLES (programme grant number EP/R034575/1) and the research project iSMART (grant number EP/K027050/1) funded by the UK Engineering and Physical Sciences Research Council (EPSRC). Dr Eminue's Postgraduate Research and was funded by the Nigerian Tertiary Education Trust Fund.

\section{References}

Allen, R.G., Pereira, L.S., Raes, D. and Smith, M. (1998) Crop evapotranspiration-Guidelines for computing crop water requirements-FAO Irrigation and drainage paper 56. FAO. 300(9), p.D05109,

AMARASIRI, A.L. and KODIKARA, J.K. (2013) Numerical modelling of a field desiccation test. Géotechnique. 63 (11), 983-986, doi:10.1680/geot.12.P.010.

An, N., Tang, C.S., Cheng, Q., Wang, D.Y. and Shi, B. (2020) Application of electrical resistivity method in the characterization of 2D desiccation cracking process of clayey soil. Eng Geol. 265, 105416, doi:10.1016/j.enggeo.2019.105416.

Anderson, M.G., Hubbard, M.G. and Kneale, P.E. (1982) The influence of shrinkage cracks on pore-water pressures within a clay embankment. Q J Eng Geol Hydrogeol. 15 (1), 9-14, doi:10.1144/GSL.QJEG.1982.015.01.03.

Ayad, R., Konrad, J.M. and Soulié, M. (1997) Desiccation of a sensitive clay: Application of the model CRACK. Can Geotech J. 34 (6), 943-951, doi:10.1139/t97-065.

Benson, A.K. (1995) Applications of ground penetrating radar in assessing some geological hazards: examples of groundwater contamination, faults, cavities. $J$ Appl Geophys. $\quad 33$ (1-3), 177-193, doi:10.1016/0926-9851(95)90040-3.

Bordoloi, S., Hussain, R., Gadi, V.K., Bora, H., Sahoo, L., Karangat, R., Garg, A. and Sreedeep, S. (2018) Monitoring soil cracking and plant parameters for a mixed grass species. Géotechnique Lett. 8 (1), 49-55, doi:10.1680/jgele.17.00145.

Cheng, Q., Tang, C.S., Zeng, H., Zhu, C., An, N. and Shi, B. (2020a) Effects of microstructure on desiccation cracking of a compacted soil. Eng Geol. 265, 105418, doi:10.1016/j.enggeo.2019.105418.

Cheng, Q., Tang, C.S., Zhu, C., Li, K. and Shi, B. (2020b) Drying-induced soil shrinkage and desiccation cracking monitoring with distributed optical fiber sensing technique. Bull Eng Geol Environ. 79 (8), 3959-3970, doi:10.1007/s10064-020-01809-8.

Costa, S., Kodikara, J. and Shannon, B. (2013) Salient factors controlling desiccation cracking of clay in laboratory experiments. Geotechnique. 63 (1), 18-29, doi:10.1680/geot.9.P.105.

Dasog, G.S., Acton, D.F., Mermut, A.R. and De 
Jong, E. (1988) Shrink-swell potential and cracking in clay soils of Saskatchewan. Can J Soil Sci. 68 (2), 251-260, doi:10.4141/cjss88025.

Decagon Devices (2016) 5TE Water Content, EC and Temperature sensor Operator's Manual. 2016. http://manuals.decagon.com/Retired and

Discontinued/Manuals/13509_5TE_Web.pdf.

Accessed 10 July 2020.

Decagon Devices (2009) MPS-1 Dielectric Water Potential Sensor Operator's Manual. 2009. http://manuals.decagon.com/Retired and Discontinued/Manuals/MPS-1-OperatorsManual-(discontinued).pdf. Accessed 10 July 2020.

Decagon Devices (2017) MPS-2 \& MPS-6 Dielectric Water Potential Sensors Operator's Manual. http://manuals.decagon.com/Retired and Discontinued/Manuals/13755_MPS-

2and6_Web.pdf. Accessed 10 July 2020.

Dyer, M., Utili, S. and Zielinski, M. (2009) Field survey of desiccation fissuring of flood embankments. Proc Inst Civ Eng - Water Manag. $162 \quad$ (3), 221-232, doi:10.1680/wama.2009.162.3.221.

Eminue, O. (2018) Environmental and material controls on desiccation cracking in engineered clay embankments. http://theses.ncl.ac.uk/jspui/handle/10443/410 1. Accessed 15 June 2020.

Gadi, V.K., Bordoloi, S., Garg, A., Sahoo, L., Berretta, C. and Sekharan, S. (2017) Effect of shoot parameters on cracking in vegetated soil. Environ Geotech. 5 (2), 123-130, doi:10.1680/jenge.17.00013.

Glendinning, S., Hughes, P., Helm, P., Chambers, J., Mendes, J., Gunn, D., Wilkinson, P. and Uhlemann, S. (2014) Construction, management and maintenance of embankments used for road and rail infrastructure: implications of weather induced pore water pressures. Acta Geotech. 9 (5), 799-816, doi:10.1007/s11440-014-0324-1.

Hen-Jones, R.M., Hughes, P.N., Stirling, R.A., Glendinning, S., Chambers, J.E., Gunn, D.A. and Cui, Y.J. (2017) Seasonal effects on geophysical-geotechnical relationships and their implications for electrical resistivity tomography monitoring of slopes. Acta Geotech. $12 \quad$ (5), 1159-1173, doi:10.1007/s11440-017-0523-7.

Holgate, T.F. (1901) Elementary Geometry, Plane and Solid, for use in High Schools and Academies. Nature. 65 (1672), 26-27, doi:10.1038/065026a0.

Hughes, P.N., Glendinning, S., Mendes, J., Parkin, G., Toll, D.G., Gallipoli, D. and Miller, P.E. (2009) Full-scale testing to assess climate effects on embankments. Proc Inst Civ Eng -

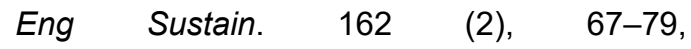
doi:10.1680/ensu.2009.162.2.67.

Julina, M. and Thyagaraj, T. (2019) Quantification of desiccation cracks using X-ray tomography for tracing shrinkage path of compacted expansive soil. Acta Geotech. 14 (1), 35-56, doi:10.1007/s11440-018-0647-4.

Levatti, H.U., Prat, P.C. and Ledesma, A. (2019) Numerical and experimental study of initiation and propagation of desiccation cracks in clayey soils. Comput Geotech. 105, 155-167, doi:10.1016/j.compgeo.2018.09.015.

Levatti, H.U., Prat, P.C., Ledesma, A., Cuadrado, A. and Cordero, J.A. (2017) Experimental analysis of 3D cracking in drying soils using ground-penetrating radar. Geotech Test J. 40 (2), 221-243, doi:10.1520/GTJ20160066.

Li, J.H. and Zhang, L.M. (2011) Study of desiccation crack initiation and development at ground surface. Eng Geol. 123 (4), 347-358, doi:10.1016/j.enggeo.2011.09.015.

Lu, Y., Liu, S., Weng, L., Wang, L., Li, Z. and Xu, L. (2016) Fractal analysis of cracking in a clayey soil under freeze-thaw cycles. Eng Geol. 208, 93-99, doi:10.1016/j.enggeo.2016.04.023.

Ng, C.W.W., Leung, A.K. and Ni, J. (2019) Plant-Soil Slope Interaction. Boca Raton, Florida, USA., CRC Press. doi:10.1201/9781351052382.

Peron, H., Delenne, J.Y., Laloui, L. and El Youssoufi, M.S. (2009a) Discrete element modelling of drying shrinkage and cracking of soils. Comput Geotech. $\quad 36 \quad$ (1-2), 61-69, doi:10.1016/j.compgeo.2008.04.002.

Peron, H., Hueckel, T., Laloui, L. and Hu, L.B. (2009b) Fundamentals of desiccation cracking of fine-grained soils: Experimental characterisation and mechanisms identification. Can Geotech J. 46 (10), 11771201, doi:10.1139/T09-054.

Ringrose-Voase, A.J. and Sanidad, W.B. (1996) A method for measuring the development of surface cracks in soils: Application to crack development after lowland rice. Geoderma. 71 (3-4), 245-261, doi:10.1016/00167061(96)00008-0.

Rivera, L.D. (2008) Comparing methods of estimating crack volume in shrink-swell soils. Texas A\&M University. http://hdl.handle.net/1969.1/98359. Accessed 7 August 2020. 
Sanchez, M., Atique, A., Kim, S., Romero, E. and Zielinski, M. (2013) Exploring desiccation cracks in soils using a 2D profile laser device. Acta Geotech. 8 (6), 583-596, doi:10.1007/s11440-013-0272-1.

Sánchez, M., Manzoli, O.L. and Guimarães, L.J.N. (2014) Modeling 3-D desiccation soil crack networks using a mesh fragmentation technique. Comput Geotech. 62, 27-39, doi:10.1016/j.compgeo.2014.06.009.

Stewart, R.D., Abou Najm, M.R., Rupp, D.E. and Selker, J.S. (2012) Measurement Tool for Dynamics of Soil Cracks. Vadose Zo J. 11 (2), vzj2011.0048, doi:10.2136/vzj2011.0048.

Stirling, R.A., Glendinning, S. and Davie, C.T. (2017) Modelling the deterioration of the near surface caused by drying induced cracking. Appl Clay Sci. 146, 176-185, doi:10.1016/j.clay.2017.06.003.

Stirling, R.A., Hughes, P., Davie, C.T. and Glendinning, S. (2015) Tensile behaviour of unsaturated compacted clay soils - A direct assessment method. Appl Clay Sci. 112-113, 123-133, doi:10.1016/j.clay.2015.04.011.

Stirling, R.A., Toll, D.G., Glendinning, S., Helm, P.R., Yildiz, A., Hughes, P.N. and Asquith, J.D. (2020) Weather-driven deterioration processes affecting the performance of embankment slopes. Géotechnique. 1-43, doi:10.1680/jgeot.19.sip.038.

Tang, C., Shi, B., Liu, C., Zhao, L. and Wang, B. (2008) Influencing factors of geometrical structure of surface shrinkage cracks in clayey soils. Eng Geol. 101 (3-4), 204-217, doi:10.1016/j.enggeo.2008.05.005.

Tang, C.S., Shi, B., Cui, Y.J., Liu, C. and Gu, K. (2012) Desiccation cracking behavior of polypropylene fiber-reinforced clayey soil. Can Geotech J. 49 (9), 1088-1101, doi:10.1139/T2012-067.

Tang, C.S., Shi, B., Liu, C., Suo, W. Bin and Gao, L. (2011) Experimental characterization of shrinkage and desiccation cracking in thin clay layer. Appl Clay Sci. 52 (1-2), 69-77, doi:10.1016/j.clay.2011.01.032.

Tang, C.S., Wang, D.Y., Zhu, C., Zhou, Q.Y., Xu, S.K. and Shi, B. (2018) Characterizing dryinginduced clayey soil desiccation cracking process using electrical resistivity method. Appl Clay Sci. 152, 101-112, doi:10.1016/j.clay.2017.11.001.

Tang, C.S., Zhu, C., Leng, T., Shi, B., Cheng, Q. and Zeng, H. (2019) Three-dimensional characterization of desiccation cracking behavior of compacted clayey soil using X-ray computed tomography. Eng Geol. 255, 1-10, doi:10.1016/j.enggeo.2019.04.014.

Tran, H.T., Wang, Y., Nguyen, G.D., Kodikara, J., Sanchez, M. and Bui, H.H. (2019) Modelling 3D desiccation cracking in clayey soils using a size-dependent SPH computational approach. Comput Geotech. 116, 103209, doi:10.1016/j.compgeo.2019.103209.

Vallejo, L.E. (2009) Fractal analysis of temperatureinduced cracking in clays and rocks. Geotechnique. 59 (3), 283-286, doi:10.1680/geot.2009.59.3.283.

Viggiani, G., Andò, E., Takano, D. and Santamarina, J.C. (2014) Laboratory X-ray Tomography: A Valuable Experimental Tool for Revealing Processes in Soils. Geotech Test J. 38 (1), 20140060, doi:10.1520/GTJ20140060.

Yu, Z., Stirling, R.A., Davie, C.T. and Eminue, O. (2020) BIONICS Cracking Data. Newcastle upon Tyne, UK, Newcastle University. Dataset. https://doi.org/10.25405/data.ncl.12820802. Accessed 18 August 2020.

Zein El Abedine, A. and Robinson, G.H. (1971) A study on cracking in some Vertisols of the Sudan. Geoderma. 5 (3), 229-241, doi:10.1016/0016-7061(71)90012-7.

Zhang, T., Deng, Y., Cui, Y., Lan, H., Zhang, F. and Zhang, H. (2019) Porewater salinity effect on flocculation and desiccation cracking behaviour of kaolin and bentonite considering working condition. Eng Geol. 251, 11-23, doi:10.1016/j.enggeo.2019.02.007. 